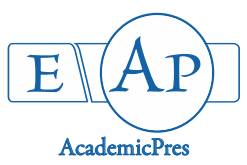

Singh S et al. (2021)

Notulae Scientia Biologicae

Volume 13, Issue 3, Article number 11028

DOI: $10.15835 / \mathrm{nsb} 13311028$

Research Article

\title{
Persistence, dissipation behavior and health risk assessment of spiromesifen in brinjal (Solanum melongena L.) by LC-MS/MS
}

\author{
Susheel SINGH ${ }^{1 *}$, Vanrajsinh SOLANKI ${ }^{1}$, Rohan KANSARA ${ }^{1}$, \\ Nitisha PATEL ${ }^{1}$, Kelvin GANDHI ${ }^{1}$, Hemant PATEL ${ }^{2}$
}

\author{
${ }^{1}$ Navsari Agricultural University, Food Quality Testing Laboratory, Navsari 396450, Gujarat, India; \\ susheelsingh@nau.in (*corresponding author);vnrj26@gmail.com; rohankansara1988@gmail.com; \\ nitishapatel210@gmail.com; kelvingandhi89@gmail.com \\ ${ }^{2}$ Navsari Agricultural University, Polytechnic Diploma College, Navsari 396450, Gujarat, \\ India; hmpatel@nau.in
}

\begin{abstract}
Brinjal (Solanum melongena) is a versatile crop infected by several insects and pests. For the control of these pests, spiromesifen insecticide has been in use to reduce the damage and increase crop production worldwide. Therefore, a field trial was conducted to study dissipation and persistence behavior of spiromesifen $22.9 \% \mathrm{w} / \mathrm{w} \mathrm{SC}$ in/on brinjal at the recommended dose (RD) $96 \mathrm{~g}$ a.i./ha and double to recommended dose $192 \mathrm{~g}$ a.i./ha (2RD). The quantitative analysis of spiromesifen was performed using ultra-high performance liquid chromatography- tandem mass spectrometry (UHPLC-MS/MS). Samples were processed by the Quick, Easy, Cheap, Effective, Rugged and Safe (QuEChERS) method. The analytical method was validated using various parameters viz., linearity $\left(\mathrm{R}^{2} \geq 0.99\right)$, sensitivity (LOD and LOQ), accuracy (recovery $\left.=70-120 \%\right)$ and precision $(\mathrm{RSD} \leq 20 \%)$. The spiroemsifen persisted up to 3 days at $\mathrm{RD}$ and 5 days at $2 \mathrm{RD}$. The dissipation halflife $\left(\mathrm{DT}_{50}\right)$ of spriromesifen was 3.64 and 4.10 days at $\mathrm{RD}$ and $2 \mathrm{RD}$ in brinjal, respectively. However, residues of spiromesifen measured from soil at $0^{\text {th }}(2 \mathrm{hr})$ day and $10^{\text {th }}$ day were below the limit of quantification (BQL). The waiting period deciphered for spiromesifen applied in brinjal was 1 day at the recommended dose. Further, health risk assessment (health risk index $<1$ and percent health index $<100$ ) was performed on the basis of field trial which suggested that the application of spiromesifen in brinjal crop at recommended dose is safe for the end-users.
\end{abstract}

Keywords: brinjal; dissipation; health risk assessment; liquid chromatography; mass spectrometry; persistence; spiromesifen

\section{Introduction}

Brinjal (Solanum melongena) is a versatile crop adapted to various agro-climatic regions which can be grown throughout the year globally. It is also usually known as eggplant and extensively cultivated in Asian countries (India, Bangladesh, Pakistan, China) and also popular in Egypt, France, Italy and United States (Cork et al., 2005 and FAOSTAT, 2019). In 2019, eggplant was the most commonly produced vegetable worldwide, contributing over 55.0 billion metric tons to global vegetable production (Anonymous, 2021). It is

Received: 14 Jul 2021. Received in revised form: 27 Jul 2021. Accepted: 09 Aug 2021. Published online: 18 Aug 2021. From Volume 13, Issue 1, 2021, Notulae Scientia Biologicae journal uses article numbers in place of the traditional method of continuous pagination through the volume. The journal will continue to appear quarterly, as before, with four annual numbers. 
an important crop of the human diet globally because its fruits are enriched with fiber, folic acid, manganese, magnesium, potassium, thaimin and vitamin B6 as well as low in fat and supply adequate calories (Muhammad et al., 2019). Farmers have been cultivating it over the years due to higher profit, relatively fast-growing capacity, and low-risk involvement and easy technological adoption (Anonymous, 2019).

Several insects and pests attack the brinjal, including mites, eggplant shoot and fruit borers, leafhoppers, ants, stem borer and epilachna beetles, which cause major crop damage and low yields about $70-80 \%$ worldwide (Ara et al., 2007, Borkakati et al., 2019 and Gautam et al., 2019). Hence, this study was conducted to find out the low-cost and effective plant-based pesticides to protect the brinjal field from pest attack.

Several insecticides viz., acephate, chlorantraniliprole, flubendiamide, imidaclopride, triazophos, monocrotophos, afidopyropen, carbofuran, chlorpyrifos, cypermethrin, deltamethrin, etc. are being used to control the damage of insects and pests in brinjal in different zones throughout the world but harmful for mankind (CIBRC, 2020). Subsequently, numerous new molecules have been developed, which degrade easily in the environment and less harmful for mankind.

A novel insecticide/acaricide, spiromesifen [3-(2,4,6-trimethylphenyl)-4-(3,3-dim-ethylbutylcarbonyloxy)-5-spirocyclo-phenyl-3-dihydro-furanol-2] is characterized as a molecule of new chemical class of spirocyclic phenyl substituted tetronic acids. It is non-systemic in nature and inhibits lipid biosynthesis in mites (Nesrine Kissoum et al., 2016). Owing to the unique chemical structure (Figure 1a), spiromesifen is an advantageous tool in resistance management in multiple cropping systems including vegetables and fruits. Spiromesifen was categorized as low acute toxic substance-exposed through different routes such as oral, dermal, inhalation, and leads to detrimental effects namely loss of body weight, effect on adrenal, thyroid, liver and spleen (EPA, 2013).

Though the spiromesifen is registered for control of red spider mite in brinjal and invariably is used by the farmers across the country but its persistence and dissipation behaviour are not available especially in the sub-tropical agro-climatic conditions in India. This study designed to develop and validate an analytical methodology for the quantification and confirmation of spiromesifen residues in brinjal using an analytical instrument LC-MS/MS. Therefore, the dissipation behaviour, persistence and health risk assessment of spiromesifen $22.9 \%$ SC in/on brinjal was reviewed under supervised field conditions.

\section{Materials and Methods}

\section{Chemicals and reagents}

The commercial insecticide formulation of Spiromesifen (22.9\% w/w SC) was purchased from a local pesticide shop, Navsari, Gujarat, India. Certified reference material of spiromesifen having purity $\geq 99.9 \%$ was procured from Sigma-Aldrich Pvt. Ltd. (Bangalore, India). MS-grade acetone, acetonitrile, magnesium sulphate, sodium chloride, sodium sulphate, methanol and water were purchased from Merck (Darmstadt, Germany). LC/MS grade ammonium formate and formic acid $\left(99.5+\%\right.$, Optima $\left.{ }^{\mathrm{Tx}}\right)$ were purchased from Fisher Chemical (Fair lawn, NJ, USA). Primary secondary amines (PSA) were procured from Supelco Sigma Aldrich (Germany). The stock solution $(1000 \mathrm{mg} / \mathrm{L})$ was prepared with acetonitrile and stored at $-20^{\circ} \mathrm{C}$. Further, this stock solution was diluted to prepare the intermediate and then formulated for working standards using methanol: water $(80: 20)$.

\section{Apparatus}

Samples were processed with the help of different apparatus including homogenizer (SRK Instruments, Gujarat, India), centrifuge (Eppendorf, Germany) and Turbovap (Caliper life science, PerkinElmer USA). The spiromesifen was analysed on Liquid Chromatography Mass Spectrometry (LCMS-QqQ), TSQ Quantum Access Max equipped with UHPLC having Dinonex Ultimate 3000 RS Pump (Thermo Fisher, USA). 


\section{Field experiment}

The Brinjal crop, var. GNRB-1(surati ravayya) was grown at Horticulture Polytechnic College farm, Navsari Agricultural University (NAU), Navsari, Gujarat, India $\left(21^{\circ} 18^{\prime} \mathrm{N}, 72^{\circ} 84^{\prime} \mathrm{E}\right.$ and $10 \mathrm{~m}$ above Mean Sea Level) by adopting Good Agricultural Practices (GAP). The spiromesifen ( $22.9 \% \mathrm{w} / \mathrm{w}$ SC) was tested as two foliar sprays at 15 days interval, the first spray was applied at the 50 percent flowering stage. Applied treatments of RD $96 \mathrm{~g}$ a.i./ha and 2RD $192 \mathrm{~g}$ a.i./ha were evaluated in reference to control (water spray only) as per Central Insecticide Board and Registration Committee (CIBRC). Data were recorded in year 2018 and 2019.

\section{Sample collection and preparation}

From each treatment across the three replications, approximately $1 \mathrm{~kg}$ brinjal fruits were picked at 0 day (2hr after application), 1, 3, 5, 7 and 10 days after the last spray of insecticide. The collected samples were packed air-tight and transported to the laboratory for pesticide residues analysis. Approximately, $1 \mathrm{~kg}$ of soil samples were collected from 5 sampling sites per treatment with standard soil sampling procedure at 0 day and 10 days (Malhat et al., 2012; Ramasubramanian, 2012b). Before analysis, soil samples were air-dried homogenized thoroughly and strained through $2 \mathrm{~mm}$ mesh sieve to remove hard stones and used for the pesticide residues analysis.

\section{Sample extraction and cleanup}

The samples were evaluated at the Pesticide Residue Wing, Food Quality Testing Laboratory, NAU, Navsari, Gujarat, India. Each sample was analysed as per the modified QuEChERS (Quick, Easy, Cheap, Effective, Rugged and Safe) method for fruits and vegetables (AOAC, 2007 and Sharma, 2013) and for soil (Asensio-Ramos et al., 2010; Sharma, 2013).

(a) Fruit: The brinjal fruit samples were cut and homogenized by a heavy-duty variable homogenizer and a representative sample $(15 \pm 0.1 \mathrm{~g})$ was taken in $50 \mathrm{~mL}$ capacity polypropylene centrifuge tubes. In the sample, $1 \%$ acetic acid in acetonitrile $(15 \mathrm{~mL})$ was added and kept in a deep freeze for 10-20 min. The mixture of $\mathrm{MgSO}_{4}(6.0 \mathrm{~g})$ and sodium acetate $(1.5 \mathrm{~g})$ added and shaken for $1.0 \mathrm{~min}$. The content was centrifuged for $2.0 \mathrm{~min}$ at $2205 \times \mathrm{g}$. The supernatant $(6.0 \mathrm{~mL})$ was transferred in $15 \mathrm{~mL}$ capacity polypropylene tubes containing anhydrous $\mathrm{MgSO}_{4}(0.9 \mathrm{~g})$ and PSA $(0.3 \mathrm{~g})$, vortexed for $1.0 \mathrm{~min}$ and then centrifuged again for 2.0 $\mathrm{min}$ at $1125 \times \mathrm{g}$. For further analysis, $2 \mathrm{~mL}$ aliquot was transferred to $15 \mathrm{~mL}$ capacity test tubes and dried with nitrogen $\left(\mathrm{N}_{2}\right)$ gas using TurboVap. Lastly, residues were reconstituted to $2 \mathrm{~mL}$ with methanol: water (80:20; $\mathrm{v} / \mathrm{v})$ for LC-MS/MS analysis. The samples were filtered through syringe filters $(0.22 \mu \mathrm{m}$, pore size $)$ before injected for quantification on the LC-MS/MS.

(b) Soil: A representative soil samples $(10 \pm 0.1 \mathrm{~g})$ were taken in $50 \mathrm{~mL}$ capacity polypropylene centrifuge tubes and $20 \mathrm{~mL}$ of acetonitrile was added into the sample. After adding $4 \mathrm{~g} \mathrm{MgSO}_{4}$ and $1.0 \mathrm{~g} \mathrm{NaCl}$, the tubes were vortexed for $1 \mathrm{~min}$ and centrifuged for $2 \mathrm{~min}$ at $2205 \times \mathrm{g}$. From this $10 \mathrm{~mL}$ aliquot was transferred to $15 \mathrm{~mL}$ centrifuge tube having $1.5 \mathrm{~g} \mathrm{MgSO}_{4}$ and $0.25 \mathrm{~g}$ PSA. The sample was centrifuged again at $1125 \times \mathrm{g}$ for $2 \mathrm{~min}$. Later, an aliquot of $4 \mathrm{ml}$ was shifted to the test tube and subjected to dryness in turbovap. Finally, spiromesifen residues were reconstituted to $2.0 \mathrm{~mL}$ with methanol: water $(80: 20 ; \mathrm{v} / \mathrm{v})$ filtered through syringe filters $(0.22 \mu \mathrm{m}$, pore size $)$.

\section{Instrumental determination}

\section{LC-MS/MS analysis}

The quantitative analysis of spiromesifen was performed on Thermo Scientific made TSQ Quantum Access MAX triple stage quadrupole mass spectrometer (MS) with a heated electrospray ionization (HESI) source. For analysis of the spiromesifen, an ultra-high performance liquid chromatograph (UHPLC) system (Model: Dionex Ultimate 3000 RS) facilitated with a quaternary pump system, an auto-sampler and column compartment were used. The separation was achieved on Hypersil Gold C18 column $(150 \times 4.6 \mathrm{~mm}, 5 \mu \mathrm{m}$ 
particle size) with a flow rate of $0.3 \mathrm{~mL} / \mathrm{min}$ at $30^{\circ} \mathrm{C}$. An elution gradient was used with solvent A: Water +5 $\mathrm{mM}$ ammonium formate $+0.1 \%(\mathrm{v} / \mathrm{v})$ formic acid and solvent B: Methanol $+5 \mathrm{mM}$ ammonium formate + $0.1 \%$ formic acid with gradient profile $(\mathrm{t}(\mathrm{min}), \% \mathrm{~A}):(0,98),(0.5,98),(2,60),(20,95),(22,95),(25,95)$.

The TSQ MS parameters of spiromesifen were optimized in positive ionization mode with capillary voltage $2950 \mathrm{~V}$, vaporizer temperature was $350^{\circ} \mathrm{C}$, sheath gas $\left(\mathrm{N}_{2}\right) 13$ arbitrary unit, aux gas $\left(\mathrm{N}_{2}\right) 7$ arbitrary unit, ion transfer capillary temperature $325^{\circ} \mathrm{C}$ and tube lens $0.70 \mathrm{~V}$. The masses were monitored and optimized using standard parameters: Precursor ion $393.0 \mathrm{~m} / \mathrm{z}$ and Product ions $294.9 \mathrm{~m} / \mathrm{z}$ (Collision energy: $14 \mathrm{eV}$ ) and $312.9 \mathrm{~m} / \mathrm{z}$ (Collision energy: $5 \mathrm{eV}$ ) (Figure $1 \mathrm{~b}$ ). The data were processed using the LCQUAN ${ }^{\mathrm{TM}} 2.9$ QF1 software (Thermo Scientific).

\section{Analytical method validation}

The method was established and performance was validated as per SANTE guidelines (SANTE, 2017) by studying the parameters (a) Linearity: The linearity of spiromesifen in solvent was obtained using five calibration standards ranging from 0.001-0.1 mg/L (0.001, 0.005, 0.010, 0.025, 0.050 and $0.100 \mathrm{mg} / \mathrm{L})$; (b) LOD and LOQ: Five repetitive responses on specific instruments for spiromesifen at different concentrations, (particularly in linear dynamic range) were recorded to establish the limit of detection (LOD) and the limit of quantification (LOQ) of the analytical method using the following formula, LOD $(\mathrm{mg} / \mathrm{kg})=($ mean of standard deviation/Slope $) \times 3$ and LOQ $(\mathrm{mg} / \mathrm{kg})=($ mean of standard deviation/Slope $) \times 10$ (Patil et al., 2018); (c) Accuracy and precision: The accuracy and precision were evaluated through a recovery study for spiromesifen. Three concentration levels of fortification for spiromesifen $(0.010,0.025$ and $0.05 \mathrm{mg} / \mathrm{kg})$ in brinjal fruit and soil were used with seven replications $(n=7)$. The consistent result of the recovery study represents the precision which can be denoted by the relative standard deviation (RSD \%).

\section{Health risk index (HRI)}

The residues obtained from brinjal fruits subjected to spray of spiromesifen at $\mathrm{RD}$ ( $96 \mathrm{~g}$ a.i./ha) and 2RD (192 g a.i./ha) were collected on 0 (2hrs) days were used to work out the different Health risk indices (HRI). The estimated daily intake (EDI) of spiromesifen residue was calculated by multiplying the product of insecticide concentration $(\mathrm{mg} / \mathrm{kg}$ ) with the average food consumption rate $(\mathrm{g} /$ day) divided by the mean body weight $(\mathrm{kg})$ of different groups of Indian consumers (Anonymous, 2011). Health risk index (HRI) was calculated using the equation: Health risk Index (HRI) = EDI/ADI (European Food Safety Authority, 2007), where $\mathrm{EDI}$ is estimated daily intake and $\mathrm{ADI}$ is acceptable daily intake. ADI value of spiromesifen is $0.03 \mathrm{mg} / \mathrm{kg}$ bw/day (FAO, 2016). Health risk index more than 1 is considered as unsafe for human health and Health Index $(\mathrm{HI})<100 \%$ represents an acceptable risk to human health (Hlihor et al., 2019).

\section{Statistical analysis}

The dissipation of spiromesifen in brinjal was calculated by using Single First Order dissipation model using the equation $\mathrm{C}_{\mathrm{t}}=\mathrm{C}_{0} \mathrm{e}^{-\mathrm{kt}}$, Where $\mathrm{C}_{\mathrm{t}}$ is insecticide concentration at time $\mathrm{t}, \mathrm{C}_{0}$ is initial concentration, $\mathrm{k}$ is the rate constant. The residues data were subjected to statistical analysis according to Hoskins (1961) to calculate the residual half-life $\left(\mathrm{DT}_{50}\right)$ and pre-harvest interval (PHI) e.g. waiting period.

\section{Results and Discussion}

\section{Method validation}

Initially, the insecticide extraction and detection method were verified based on data include linearity, LOD, LOQ, accuracy and precision (SANTE, 2017). After injecting working standard solution of spiromesifen $(0.005 \mathrm{mg} / \mathrm{kg})$ into the UHPLC, retention time (RT) was obtained $19.23 \mathrm{~min}$. In chromatogram, no other peaks were observed indicating the absence of any interfering matrix compounds (Figure 1d). The 
maximum residue limits (MRLs) for pesticide in food was considered to ensure that the method was suitable for the determination of pesticide residue contents. The MRL of spiromesifen in brinjal is $0.5 \mathrm{mg} / \mathrm{kg}$ (European Food Safety Authority, 2019).

Table 1. Method validation parameters of spiromesifen in brinjal fruit and soil

\begin{tabular}{|c|c|c|c|c|c|}
\hline \multirow{2}{*}{$\begin{array}{c}\text { Sr } \\
\text { No. }\end{array}$} & \multirow{2}{*}{ Parameters } & \multirow{2}{*}{ Particular } & \multicolumn{3}{|c|}{ Spiromesifen } \\
\hline & & & & uit & Soil \\
\hline \multirow{3}{*}{1} & \multirow{3}{*}{$\begin{array}{l}\text { Linearity } \\
\qquad(n=6)\end{array}$} & Calibration concentration range & \multicolumn{3}{|c|}{$0.001-0.1 \mathrm{mg} / \mathrm{L}$} \\
\hline & & Regression equation & $y=5$ & $x+11709$ & $y=91859 x+1331.1$ \\
\hline & & $R^{2}\left\{R^{2} \geq 0.99\right\}$ & & 999 & 0.995 \\
\hline \multirow{2}{*}{2} & \multirow{2}{*}{$\begin{array}{l}\text { Sensitivity } \\
\quad(n=6)\end{array}$} & $\mathrm{LOD}(\mathrm{mg} / \mathrm{kg})$ & \multicolumn{2}{|c|}{0.002} & 0.003 \\
\hline & & $\mathrm{LOQ}(\mathrm{mg} / \mathrm{kg})[\mathrm{LOQ}<\mathrm{MRL}]$ & \multicolumn{2}{|c|}{0.009} & 0.009 \\
\hline \multirow{4}{*}{3} & \multirow{4}{*}{$\begin{array}{l}\text { Accuracy } \\
(n=7)\end{array}$} & \multirow{4}{*}{$\begin{array}{l}\text { \% Recovery } \\
{[70-120 \%]}\end{array}$} & $\begin{array}{c}\text { F level } \\
(\mathrm{mg} / \mathrm{kg})\end{array}$ & $\%( \pm S D)$ & $\%( \pm S D)$ \\
\hline & & & 0.010 & $103.95 \pm 9.79$ & $75.86 \pm 13.99$ \\
\hline & & & 0.025 & $95.66 \pm 13.98$ & $86.51 \pm 11.61$ \\
\hline & & & 0.050 & $92.35 \pm 14.91$ & $97.15 \pm 11.83$ \\
\hline \multirow{4}{*}{4} & \multirow{4}{*}{$\begin{array}{l}\text { Precision } \\
\quad(n=7)\end{array}$} & \multirow{4}{*}{$\begin{array}{c}\% \text { RSD } \\
{[\leq 20 \%]}\end{array}$} & $\begin{array}{c}\text { F level } \\
(\mathrm{mg} / \mathrm{kg})\end{array}$ & $\%$ & $\%$ \\
\hline & & & 0.010 & 9.42 & 18.44 \\
\hline & & & 0.025 & 14.62 & 9.26 \\
\hline & & & 0.050 & 16.15 & 12.18 \\
\hline
\end{tabular}

$\mathrm{R}^{2}$ : correlation coefficient; LOQ: Limit of quantification; LOD: Limit of detection; F level: Fortification level; \pm SD: Standard deviation; RSD: Relative standard deviation; MRL: maximum residue limit $(0.5 \mathrm{mg} / \mathrm{kg}$ for spiromesifen in brinjal); Values given in parenthesis [ ] and \{\} are the standard acceptance criteria as per SANTE, 2017

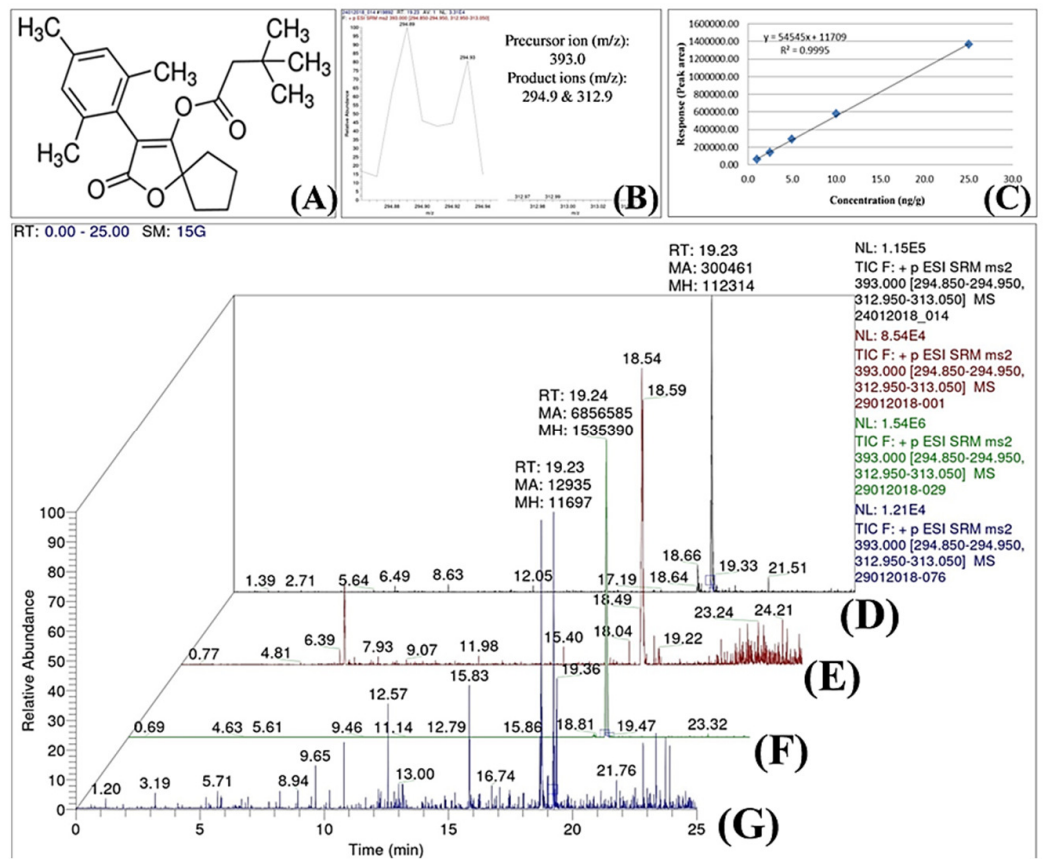

Figure 1. Optimization of chromatographic separation on UHPLC-MS/MS SRM of spiromesifen (A) Chemical structure (B) Optimized precursor and product $(\mathrm{m} / \mathrm{z})$ ions $(\mathrm{C})$ Specificity with linear response. UHPLC-MS/MS SRM three dimensional chromatograms of spiromesifen (D) at standard $0.005 \mathrm{mg} / \mathrm{kg}(\mathrm{E})$ in control (F) on 0 (2hr) day and $(\mathrm{G})$ on $3^{\text {rd }}$ day after spiromesifen application in brinjal fruit sample at recommended dose; RT: Retention Time; MH: Peak Height; MA: Peak Area 
The linearity studies of spiromesifen at different levels (0.001, 0.005, 0.010, 0.025, 0.050 and 0.100 $\mathrm{mg} / \mathrm{L})$ in methanol: water $(80: 20 ; \mathrm{v} / \mathrm{v})$ on LC-MS/MS as well as in blank brinjal fruit and soil extracts (i.e., in matrix-matched solutions) showed a linear response (Table 1 and Figure 1c). The correlation coefficient $\left(\mathrm{R}^{2}\right)$ value of spiromesifen was 0.999 and 0.995 for brinjal fruit and soil (Table 1). The obtained values were in accordance with the acceptable limit of $\mathrm{R}^{2} \geq 0.99$ and deviation of back calculated concentration from true concentration was $\leq 20 \%$.

The LOD value of spiromesifen in brinjal fruit worked out was $0.002 \mathrm{mg} / \mathrm{kg}$, while the LOQ value obtained was $0.009 \mathrm{mg} / \mathrm{kg}$ (Table 1). The observed LOQ value of spiromesifen was lower than maximum residue limit (MRL) values fixed for brinjal. It indicates that the instrument was sensitive enough to abide the internationally acceptable standard. The LOD value of spiromesifen in soil recorded was $0.003 \mathrm{mg} / \mathrm{kg}$. The corresponding LOQ value worked out for spiromesifen was $0.009 \mathrm{mg} / \mathrm{kg}$ (Table 1).

The recovery of spiromesifen was ranged from 92.35 to $103.95 \%$ in brinjal fruit and 75.86 to $97.15 \%$ in soil, while the RSDs were ranged from 9.42 to $18.44 \%$ in brinjal fruit and soil (Table 1). All recoveries (70$120 \%)$ and RSDs $(\leq 20 \%)$ results were obtained within the acceptable measures of SANTE guidelines.

\section{Residue analysis}

The persistence and dissipation pattern of spiromesifen in brinjal under sub-tropical agro-climatic conditions is depicted in Table 2. The spiromesifen residues in control samples (water spray only) were not detected (Fig. 1e), however, in treated samples on 0 day (2hr) was 0.091 and $0.192 \mathrm{mg} / \mathrm{kg}$ at RD and 2RD, respectively. The initial residues of spiromesifen steadily and progressively dissipated which were 0.024 and $0.079 \mathrm{mg} / \mathrm{kg}$ on $3^{\text {rd }}$ day, respectively at both doses. It shows $31.86-87.50 \%$ loss of spiromesifen residue (Table 2; Fig. $1 \mathrm{f}$ and $\mathrm{g}$ ). Thereafter, the residue of the spiromesifen was not detected at 5 days and 7 days at RD. While on the $5^{\text {th }}$ day, spiromesifen residue was $0.024 \mathrm{mg} / \mathrm{kg}$, and on the $7^{\text {th }}$ day, it was below quantitation level (BQL) at $2 \mathrm{RD}$ (Table 2).

Table 2. Residues and dissipation pattern of spiromesifen in brinjal fruit and soil

\begin{tabular}{|c|c|c|c|}
\hline \multirow{2}{*}{$\begin{array}{c}\text { Days after Application } \\
\text { (days) }\end{array}$} & \multicolumn{3}{|c|}{ Average residues of spiromesifen $(\mathrm{mg} / \mathrm{kg})$ in fruit } \\
\hline & Control & 96 g a.i./ha $(\mathrm{RD})^{\mathrm{a}}$ & 192 g a.i./ha $(2 \mathrm{RD})^{\mathrm{b}}$ \\
\hline $0(2 \mathrm{hr})$ & ND & $\begin{array}{l}0.091 \\
(0.00)\end{array}$ & $\begin{array}{l}0.192 \\
(0.00)\end{array}$ \\
\hline 1 & ND & $\begin{array}{c}0.062 \\
(31.86) \\
\end{array}$ & $\begin{array}{c}0.115 \\
(40.10) \\
\end{array}$ \\
\hline 3 & ND & $\begin{array}{c}0.024 \\
(73.62)\end{array}$ & $\begin{array}{c}0.079 \\
(58.85)\end{array}$ \\
\hline 5 & ND & BQL & $\begin{array}{c}0.024 \\
(87.50) \\
\end{array}$ \\
\hline 7 & ND & BQL & BQL \\
\hline 10 & ND & BQL & $\mathrm{BQL}$ \\
\hline Dissipation equation & - & $y=-0.1902 x+1.9723$ & $y=-0.1689 x+2.2877$ \\
\hline Correlation coefficient $\left(\mathrm{R}^{2}\right)$ & - & 0.998 & 0.953 \\
\hline $\mathrm{DT}_{50}$ (days) & - & 3.64 & 4.10 \\
\hline Waiting Period (days) & - & 1.0 & 1.0 \\
\hline \multicolumn{4}{|c|}{ Average residues $(\mathrm{mg} / \mathrm{kg})$ in Soil } \\
\hline $0(2 \mathrm{hr})$ & ND & $\mathrm{BQL}$ & BQL \\
\hline 10 & ND & BQL & $\mathrm{BQL}$ \\
\hline
\end{tabular}

a: Recommended dose; b: Double to the recommended dose; Values given in parenthesis () represents percent degradation of pesticide residues over residues obtained on 0 day ( 2 hrs after application); ND: Not detected; BQL: Below quantitation level ( $<\mathrm{LOQ})$; LOQ: Limit of quantitation; $\mathrm{DT}_{50}$ : Half-life values; Spiromesifen residue data are mentioned as mean of year 2018 and 2019 
The dissipation regression equations for spiromesifen were $y=-0.1902 x+1.9723$ and $y=-0.1689 x+$ 2.2877 at $\mathrm{RD}$ and $2 \mathrm{RD}$, respectively as mentioned in Table 2 . The dissipation half-life $\left(\mathrm{DT}_{50}\right)$ worked out for spiromesifen were 3.64 and 4.10 days at $\mathrm{RD}$ and $2 \mathrm{RD}$, respectively (Table 2). As per classifications based on agro-climatic conditions, Navsari is located in South Gujarat comes under heavy rainfall zone-I (Agroecological situation-III). This zone's climate is typically sub-tropical, with a humid and warm monsoon with heavy rains, somewhat cold winter and rather hot summer.

The contemporary finding on $\mathrm{DT}_{50}$ of spiromesifen is differing from the results reported with $\mathrm{DT}_{50}$ for brinjal 1.40-2.18 days (Vinothkumar et al., 2018) and other fruits and vegetables like, green chilli 2.18-2.40 days (Sharma et al., 2007), okra 1.65-1.68 days (Raj et al., 2012), tomato 0.93-1.38 days (Sharma et al., 2014) and cucumber 2.12-2.19 days (Banerjee and Agyani, 2019). This variation could be the effect of the major environmental factors and processes viz., relative humidity, temperature, wind, volatilization and photodegradation at field conditions (Sharma et al., 2014; Mate et al., 2015; Vinothkumar et al., 2018; Banerjee and Agyani, 2019; Solanki et al., 2019) which are not reliable in different geographical zones.

The spiromesifen residues detected in soil were BQL at $\mathrm{RD}$ and $2 \mathrm{RD}$ on 0 day ( $2 \mathrm{hr}$ ), respectively (Table 2). Meanwhile, spiromesifen was not directly applied to soil; its residues in soil were also BQL at the $10^{\text {th }}$ day. A less similar finding was also reported by Sharma et al. (2014), where spriomesifen residues were quantified up to 15 days in tomato soil when it was applied at $\mathrm{RD}$ ( $150 \mathrm{~g}$ a.i./ha) and $2 \mathrm{RD}$ ( $300 \mathrm{~g}$ a.i./ha) under different agro-climatic zones of India. Spiromesifen as an acaricide, is believed to be subjected to degradation from their moiety in the plant and different kinds of soils (Mate et al., 2015). Different studies demonstrate that spiromesifen is rapidly degraded in soil and aqueous thoroughly metabolized to the final degradation product carbon dioxide. Major metabolites involved in the degradation are Sp-enol and 4-carboxy-Sp-enol (FAO, 2016). Consequently, spiromesifen unveils minute persistence behavior in different matrices and also it might be a potential reason for its faster degradation, when applied at $\mathrm{RD}$ and $2 \mathrm{RD}$.

\section{Health risk assessment}

Generally, brinjal fruits are preferred by consumers and also used as a favorite home food in delicious cuisines of vegetarian and non-vegetarian people. Pesticides are a major part of different chemicals applied to the fruits. When pesticides exceed the maximum residue limit (MRL) on food crops, it could generate difficulty to the exporters and local consumers. Therefore, health risk estimations were studied based on pesticide residues detected in brinjal fruits. The health risk index (HRI) was calculated by dividing the EDI $\left(\mathrm{mg} \mathrm{kg}^{-1} /\right.$ day) by their corresponding values of acceptable daily intakes (ADI) for agricultural and veterinary chemicals (Anonymous, 2005). The average values of individual body weights involving different age groups in India are listed according to the official dietary guideline for Indians (Anonymous, 2011). Cumulative estimated health risk index values as well as Health Index (HI \%) of spiromesifen residues recorded at $\mathrm{RD}$ and $2 \mathrm{RD}$, are presented in Table 3. 
Table 3. Health risk assessment of spiromesifen in brinjal for different groups of Indian consumers

\begin{tabular}{|c|c|c|c|c|c|c|c|c|c|}
\hline \multirow{3}{*}{ Group } & \multirow{3}{*}{$\begin{array}{c}\text { Particulars } \\
\text { with age }\end{array}$} & \multirow{3}{*}{$\begin{array}{c}\text { Food } \\
\text { consumption } \\
\text { (g/day) }\end{array}$} & \multirow{3}{*}{$\begin{array}{c}\text { Body } \\
\text { weight } \\
(\mathrm{kg})\end{array}$} & \multicolumn{6}{|c|}{ Dietary risk assessment } \\
\hline & & & & \multicolumn{3}{|c|}{96 g a.i./ha $(\mathrm{RD})$} & \multicolumn{3}{|c|}{192 g a.i./ha (2 RD) } \\
\hline & & & & EDI & HRI & $\% \mathrm{HI}$ & EDI & HRI & $\% \mathrm{HI}$ \\
\hline \multirow{3}{*}{ Children } & $1-3$ years & 30 & 12.90 & 0.001 & 0.024 & 2.40 & 0.001 & 0.050 & 5.00 \\
\hline & 4-6 years & 30 & 18.00 & 0.001 & 0.017 & 1.70 & 0.001 & 0.036 & 3.60 \\
\hline & $7-9$ years & 60 & 25.10 & 0.000 & 0.012 & 1.20 & 0.001 & 0.025 & 2.50 \\
\hline Boys & $10-12$ years & 60 & 34.30 & 0.000 & 0.009 & 0.90 & 0.001 & 0.019 & 1.90 \\
\hline Girls & $10-12$ years & 60 & 35.00 & 0.000 & 0.009 & 0.90 & 0.001 & 0.018 & 1.80 \\
\hline Boys & $13-15$ years & 75 & 47.60 & 0.000 & 0.006 & 0.60 & 0.000 & 0.013 & 1.30 \\
\hline Girls & $13-15$ years & 60 & 46.60 & 0.000 & 0.007 & 0.70 & 0.000 & 0.014 & 1.40 \\
\hline Boys & $16-18$ years & 90 & 55.40 & 0.000 & 0.005 & 0.50 & 0.000 & 0.012 & 1.20 \\
\hline Girls & $16-18$ years & 75 & 52.10 & 0.000 & 0.006 & 0.60 & 0.000 & 0.012 & 1.20 \\
\hline \multirow{3}{*}{ Men } & Sedentary work & 75 & \multirow{3}{*}{60.00} & 0.000 & 0.004 & 0.40 & 0.000 & 0.008 & 0.80 \\
\hline & Moderate work & 90 & & 0.000 & 0.005 & 0.50 & 0.000 & 0.010 & 1.00 \\
\hline & Heavy work & 120 & & 0.000 & 0.006 & 0.60 & 0.000 & 0.013 & 1.30 \\
\hline \multirow{3}{*}{ Women } & Sedentary work & 60 & \multirow{3}{*}{55.00} & 0.000 & 0.003 & 0.30 & 0.000 & 0.007 & 0.70 \\
\hline & Moderate work & 75 & & 0.000 & 0.004 & 0.40 & 0.000 & 0.009 & 0.90 \\
\hline & Heavy work & 90 & & 0.000 & 0.005 & 0.50 & 0.000 & 0.010 & 1.00 \\
\hline
\end{tabular}

RD: Recommended dose; 2RD: Double to the Recommended dose; EDI: estimated daily intake; HRI: Health Risk Index; HI: Percent Health Index

Thus, it reflects that under the tropical agro-climatic conditions from 0 days after spray at both doses, the HRI values are lower than 1 and HI\% are less than 100\%. It indicates that the Spiromesifen $22.9 \%$ (w/w SC) will not cause any adverse effect after consumption of brinjal fruits. Therefore, the consumption of brinjal laced with product of Spriomesifen ( $22.9 \% \mathrm{w} / \mathrm{w}$ SC) at recommended dose with an observed waiting period of 1 day is safer as their HRI values are lower than 1.

\section{Conclusions}

The goal of the current study was to assess the dissipation behaviour of spiromesifen in brinjal in order to suggest the use of formulation Spiromesifen (22.9 \% w/w SC) to assure safe brinjal intake. At RD, spiromesifen residues in brinjal lasted up to three days. The $\mathrm{DT}_{50}$ of spiromesifen in brinjal was 3.64-4.10 days at $\mathrm{RD}$ and $2 \mathrm{RD}$. The waiting period worked out for spiromesifen was 1 day at $\mathrm{RD}$. When the formulation product Spiromesifen $(22.9 \% \mathrm{w} / \mathrm{w}$ SC) is sprayed twice at 15 -day intervals commencing from $50 \%$ flowering stage at $96 \mathrm{~g}$ a.i./ha $(\mathrm{RD})$ to control insect pests under sub-tropical agro-climatic conditions in India, it is recommended to wait at least one day. In order to address the issue of food safety, the health risk assessment (HRI) was evaluated, which demonstrated that one-day waiting period is sufficient to eliminate the toxic effects of the spiromesifen on consumers, since HRI and HI were less than 1 and $100 \%$ from 0 day, respectively. As a result, it can be stated that spiromesifen spray at recommended dose poses no risk to the target consumers.

\section{Authors' Contributions}

Conceptualization of research (SS and VS); Designing of the experiments (SS); Contribution of experimental materials (HP); Execution of field/lab experiments and data collection (KG and NP); Analysis of data and interpretation (VS, RK and KG); Preparation of the manuscript (VS, RK and NP). All authors read and approved the final manuscript. 


\section{Acknowledgements}

The authors are grateful to the In-charge Professor and Head of Polytechnic Horticulture, Navsari Agricultural University, Navsari, Gujarat, India for their support and assistance in conducting the field trial. This research received no specific grant from any funding agency in the public, commercial, or not-for-profit sectors.

\section{Conflict of Interests}

The authors declare that there are no conflicts of interest related to this article.

\section{References}

Anonymous (2005). Acceptable daily intakes for agricultural and veterinary chemicals. Australian Government, Office of chemical safety. Department of Health and Ageing pp 1-113.

Anonymous (2011). Dietary guidelines for Indian - a manual. National Institute of Nutrition, ICMR publication. pp 1139.

Anonymous (2021). Retrieved 2021 June 14 from https://www.statista.com/statistics/264065/global production-ofvegetables-by-type/

Anonymous (2019). Retrieved 2021 June 14 from https://www.agrifarming.in/brinjal-farming-profit-cost-yield incomeeggplant.

AOAC Method (2007). Official Methods of Analysis 2007.01, Pesticide Residues in Foods by Acetonitrile Extraction and Partitioning with Magnesium Sulfate. Retrieved 2021 march 14 from: http://www.weber:hu/PDFs/QuEChERS/AOAC_2007_01.pdf.

Ara, S, Nahar N, and Rahman M (2007). Incidence and damage estimation of brinjal shoot and fruit borer in five different brinjal varieties. Progressive Agriculture 18(2): 75-80. http://doi.org/10.3329/PA.V18I2.18162

Asensio-Ramos M, Hernandez-Borges J, Ravelo-Perez LM and Rodriguez-Delgado MA (2010). Evaluation of a modified $\mathrm{QuEChERS} \mathrm{method} \mathrm{for} \mathrm{the} \mathrm{extraction} \mathrm{of} \mathrm{pesticides} \mathrm{from} \mathrm{agricultural,} \mathrm{ornamental} \mathrm{and} \mathrm{forestal} \mathrm{soils.} \mathrm{Analytical}$ and Bioanalytical Chemistry 396:2307-2319. https://doi:.org/10.1007/s00216-009-3440-2

Banerjee T, Agyani MK (2019). Risk assessment and persistence evaluation of Spiromesifen 240 SC on cucumber in India. International Journal of Postharvest Technology and Innovation 6(1):11-25. https://doi.org/10.1504/IJPTI.2019.104175

Borkakati RN, Venkatesh MR, Saikia DK (2019). Insect pests of Brinjal and their natural enemies. Journal of Entomology and Zoology Studies 7(1): 932-937.

Central Insecticide Board and Registration committee (2020) Approved Uses of Registered Insecticides Major uses of pesticides registered under the Insecticides Act, 1968. Retrieved 2020 March 16 from http://ppqs.gov.in/sites/default/files/major_use_of_pesticides_insecticides.pdf

Cork A, Alam SN, Talekar K, Talekar NS (2005). Development and commercialization of mass trapping for control of eggplant borer, Leucinodes orbonalis in South Asia. Indian Institute of Vegetable Research. http://doi.org/10.1079/ber2005389

EPA Environmental Protection Agency (2013). Retrieved 2021 June 30 from https://www.federalregister.gov/documents/2013/01/16/2013-00728/spiromesifen-pesticide-tolerances

European Food Safety Authority (EFSA) (2019). Retrieved 2021 June 19 from https://efsa.onlinelibrary.wiley.com/doi/full/10.2903/j.efsa.2019.5579

The Food and Agriculture Organization Corporate Statistical Database (FAOSTAT) (2019). Retrieved 2021 June 19 from http://www.fao.org/faostat/en/\#data/QI

Food and Agriculture Organization (FAO) (2016). Retrieved 2021 June 19 from http://www.fao.org/fileadmin/templates/agphome/documents/Pests_Pesticides/JMPR/Evaluation2016/SPI OMESIFEN.pdf 
Food and Agriculture Organization (FAO) (2016). Spiromesifen ADI. Retrieved 2020 October 6 from http://www.fao.org/fileadmin/templates/agphome/documents/Pests_Pesticides/JMPR/Evaluation2016/SPI ROMESIFEN.pdf

Gautam M, Kafle S, Regmi B, Thapa G, Paudel S (2019). Management of brinjal fruit and shoot borer (Leucinodes orbonalis Guenee) in Nepal. Acta Scientific Agriculture 3(9):188-195. http://doi.org/10.31080/ASAG.2019.03.0632

Hoskins WM (1961). Mathematical treatment of loss of pesticide residues. Plant Protection Bulletin 9:163-168. http://doi.org/10.12691/env-2-3-2

Kissoum N, Soltani N (2016). Spiromesifen, an insecticide inhibitor of lipid synthesis, affects the amounts of carbohydrates, glycogen and the activity of lactate dehydrogenase in Drosophila melanogaster. Journal of Entomology and Zoology Studies 4(1):452-456.

Hlihor RM, Pogacean MO, Rosca M, Cozma P, Gavrilescu M (2019). Modelling the behavior of pesticide residues in tomatoes and their associated long-term exposure risks. Journal of environmental management 233:523-259. http://doi.org/10.1016/j.jenvman.2018.11.045

Malhat F, Abdallah H, Hegazy I (2012). Dissipation of chlorantraniliprole in tomato fruits and soil. Bulletin of Environmental Contamination and Toxicology 88:349-351. http://doi.org/10.1007/s00128-011-150465-y

Mate CJ, Mukherjee I, Das SK (2015). Persistence of spiromesifen in soil: influence of moisture, light, $\mathrm{pH}$ and organic amendment. Environmental Monitoring and Assessment. 187(2):1-12. http://doi.org/10.1007/s10661-0144207-6

Naeem MY, Ugur S (20190. Nutritional content and health benefits of eggplant. Turkish Journal of Agriculture-Food Science and Technology 29(7):31-36. https://doi.org/10.24925/turjaf.v7isp3.31-36.3146

Patil VM, Singh S, Patel KG, Patel ZP (2018). Effect of sun drying and grinding on the residues of six insecticides in chilli fruits. Pesticide Research Journal 30(2):140-6. https://doi.org/10.5958/2249-524X.2018.00023.7

Raj MF, Solanki PP, Singh S, Vaghela KM, Shah PG, Patel AR, Diwan KD (2012). Dissipation of spiromesifen in/on okra under middle Gujarat conditions. Pesticide Research Journal 24(1):25-27.

Ramasubramanian T, Paramasivam M, Salin KP, Jayanthi R (2012b). Dissipation kinetics of chlorantraniliprole in soils of sugarcane ecosystem. Bulletin of Environmental Contamination and Toxicology 89(6):1268-1271. https://doi.org/10.1007/s00128-012-0855-9

SANTE (2017) Guidance document on analytical quality control and method validation procedures for pesticide residues analysis in food and feed. Retrieved 2020 October 5 from https://www.eurlpesticides.eu/docs/public/tmplt_article.asp?CntID $=727$

Sharma KK, Mukherjee I, Singh B, Mandal K, Sahoo SK, Banerjee H, ... Patel AR (2014). Persistence and risk assessment of spiromesifen on tomato in India: a multilocational study. Environmental Monitoring and Assessment 186(12):8453-61. https://doi.org/10.1007/s10661-014-4016-y

Sharma KK, Rao CS, Dubey JK, Patyal SK, Parihar NS, Battu RS, Sharma V, Gupta P, Kumar A, Jaya M, Singh B (2007). Persistence and dissipation kinetics of spiromesifen in chili and cotton. Environmental Monitoring and Assessment. 132(1):25-31. https://doi.org/10.1007/s10661-006-9499-8

Sharma KK (2013). Pesticide residues analysis manual, IARI, New Delhi, pp 92-94.

Solanki VH, Singh S, Gandhi KD, Patel KG and Patel KN (2019). Persistence behaviour of pre-mix formulation of profenophos and cypermethrin in/on sapota fruit. International Journal of Current Microbiology and Applied Sciences 8(1):1250-1260. https://doi.org/10.20546/ijcmas.2019.801.132

Vinothkumar B, Shibani PV, Kaviya R, Kowshika J (2018). Dissipation pattern of spiromesifen in/on brinjal fruits. International Journal of Chemical Studies 6:2485-2488.

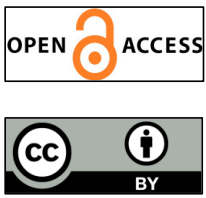

The journal offers free, immediate, and unrestricted access to peer-reviewed research and scholarly work. Users are allowed to read, download, copy, distribute, print, search, or link to the full texts of the articles, or use them for any other lawful purpose, without asking prior permission from the publisher or the author.

License - Articles published in Notulae Scientia Biologicae are Open-Access, distributed under the terms and conditions of the Creative Commons Attribution (CC BY 4.0) License.

(c) Articles by the authors; SHST, Cluj-Napoca, Romania. The journal allows the author(s) to hold the copyright/to retain publishing rights without restriction. 